\title{
Nachruf Ao. Univ.-Prof. i. R. Dipl.-Ing. Dr. mont. Karl Leopold Maurer
}

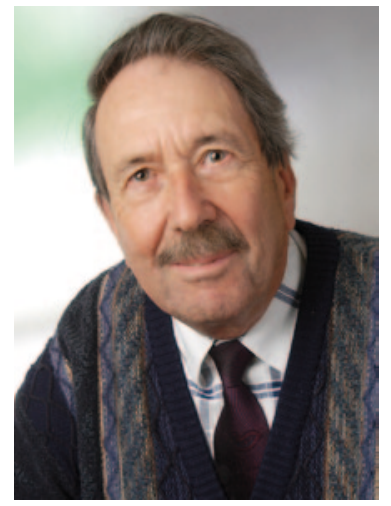

Foto Wilke, Leoben

Herr Ao. Univ.-Prof. i. R. Dipl.-Ing. Dr. mont. Karl Leopold Maurer ist am Samstag, den 31. Mai 2014, im Alter von 87 Jahren in Leoben verstorben.

Prof. Maurer wurde 1927 in Waltenberg bei Graz geboren. Aufgrund seines Militärdienstes und russischer Gefangenschaft konnte er die Reifeprüfung erst 1947 ablegen. Danach nahm Karl Maurer das Studium an der Montanistischen Hochschule Leoben, Fachrichtung "Hüttenwesen“, auf. Anschließend wurde er Hochschulassistent und begann mit seiner Dissertation, die er 1962 mit der Promotion abschloss. In dieser Zeit und in den darauf folgenden Jahren beschäftigte sich Karl Maurer intensiv mit allen Aspekten der Werkstoffprüfung, die später den Schwerpunkt seiner Habilitation darstellten. Im Jahr 1967 wurde er Hochschuldozent mit der Verleihung der Dozentur für "Metallkundliche Werkstoffprüfung". Nach einer Tätigkeit als Oberassistent wurde er 1973 zum Ao. Universitätsprofessor ernannt. Gleichzeitig wurde er zum Leiter der Abteilung für „Werkstoffprüfung und Elektronenmikroskopie“ bestellt. Vor allem durch seine Tätigkeit im Bereich der Schadensanalyse machte sich Karl Maurer einen wissenschaftlichen Namen und war ein anerkannter Gutachter bei komplexen Schadensfällen. Seine Vorlesungen über Bruchmechanik und Werkstoffprüfung haben Generationen von Studenten begeistert und nachhaltig geprägt. 1976 war Karl Maurer ein Gründungsmitglied der internationalen Tagung „Gefüge und Bruch“, die seit dieser Zeit regelmäßig veranstaltet wird. Auch sportlich war Karl Maurer sehr aktiv. So hat er z. B. die Paddlergruppe an der Montanuniversität aufgebaut und viele Jahre lang betreut. Nach dem Weggang von Prof. Fischmeister übernahm er für kurze Zeit die Leitung des Institutes für Metallkunde und Werkstoffprüfung. Im November 1992 beging Karl Maurer sein 40. Dienstjubiläum. Mit Ende desselben Jahres wurde er in den Ruhestand versetzt, was ihn aber nicht abhielt, noch viele Jahre als Gutachter und Experte für Schadensfälle tätig zu sein. In seiner gesamten Laufbahn hat er über 3000 Schadensfälle für die metallerzeugende, -verarbeitende und -anwendende Industrie, besonders in Österreich, untersucht. Prof. Karl Leopold Maurer hinterlässt seine Gattin und zwei Söhne.

Helmut Clemens

Christian Mitterer 